\title{
Intravitreal air in aphakic retinal detachment
}

\author{
HEGTOR B. CHAWLA \\ Princess Alexandra Eye Parilion, Royal Infirmary, Edinburgh
}

The use of intravitreal air, first mentioned by Arruga (1936), is not popular in the treatmen of aphakic retinal detachments for two basic reasons:

(I) The air may move the iris diaphragm forwards-causing an angle-block glaucoma.

(2) The air itself may escape into the anterior chamber and remain there.

The injection of air in cases of phakic retinal detachment is well known (Rosengreng I938), but sadly does not enjoy wide usage. My present phakic technique consists of monitored cryopexy to the retinal tears, release of subretinal fluid through a scratc sclerotomy, and injection of sterile air through the pars plana. A No. 40 silicone banf may or may not be placed around the eye.

The patient's posture after the operation is arranged in such a way that the air presses the retinal tears upwards against the treated choroid. To use the technique successfully an $\mathbb{A}^{\circ}$ to avoid an unpleasant position for the patient postoperatively, it should be used wher the retinal tears lie between the 8 and the 4 o'clock meridians superiorly. In addition, the eye must be made sufficiently hypotonic to make room for the $\mathrm{I}$ and $3 \mathrm{ml}$. of air which is injected. This latter requirement is vital and the whole technique is described in detail io the following paper (Chawla and Birchall, I973).

The present paper discusses eight patients who have suffered aphakic retinal detachmento All were treated with intravitreal air injection, monitored cryopexy, and an encircling No. 40 silicone band. An in-depth study of their lens extractions and subsequent detach ments is not strictly relevant, since the main aim is to demonstrate and restate the toleranco of the aphakic eye to intravitreal air.

\section{Case reports}

Case r, a 68-year-old woman, suffered an almost total detachment in October, 1970, 18 month after lens extraction. The retro-oral tear lay on the io o'clock meridian.

A broad encircling sponge failed to contain the detachment and large choroidal detachment followed. At this point it was thought that the vision was lost, and air was injected at the limbuss into the anterior chamber, the eye being markedly softened by removal of the sponge. The air moved into the vitreous cavity on correct posturing and remained there. The tear was later seale必 with cryopexy and a radial sponge, and the visual acuity at present is $6 / 9$.

Although this case was not classically treated with intravitreal air, it demonstrated the possibility of its use.

The subsequent seven cases were as follows:

Case 2, a 79-year-old male myope, was seen in January, 197 I, with an upper temporal retina용 detachment in the left and only eye. The sclera was very thin. A strip of guttered silicone wa䣄 placed deep to the No. 40 band to prevent erosion. The retina was flat at the end of the opero ation, and the visual result was $6 / 9$. 
Case 3, a 69-year-old man, seen in April, 1971, had had two previous cerclage operations. There was a retinal detachment from an equatorial tear at 3 o'clock behind the buckle. Light coagulation was given before the operation. The retina was flat at the end of the operation, and the visual result was $6 / 60$.

Case 4, a 40-year-old man, seen in August, I97 I, had needled congenital cataracts and total retinal detachment with signs of vitreous retractions. He had had two previous operations elsewhere with radial sponge and cerclage. The retina was flat at the end of the operation, and the visual result was counting fingers (vitreous haze ++ ).

Case 5, a 6o-year-old woman, seen in September, 1971, had had a previous upper temporal circumferential sponge buckle. Retinal detachment was almost total with a tear behind the buckle. The retina was flat postoperatively and the visual result was $6 / \mathrm{r} 8$.

Case 6, a 65-year-old man, seen in August, I.97 r. had an upper tear with large operculum and vitreous retraction and total retinal detachment. The retina was flat at the end of the operation, but he has suffered a recent recurrence of the retinal detachment.

Case 7, an 80-year-old man, seen in August, $197 \mathrm{I}$, had a temporal retinal detachment, with a series of retro-oral tears; he had had a complete iridectomy. The retina was flattening at the end of the operation, and the visual result was $6 / 6$.

Case 8, a 75-year-old woman, was seen in October, $197 \mathrm{I}$, had subtotal retinal detachment, two retro-oral tears at 10 and 6 o'clock and massive postoperative vitreous retraction. The retina was flat at the end of the operation, and the visual result was hand movements, but she has suffered a recurrent retinal detachment.

\section{Discussion}

The aphakic eye, even with a sector iridectomy (Case 7), will retain air in the vitreous cavity provided the equator is at a higher level than the limbus. This position is physically possible with all superior tears between the 8 and 4 o' clock meridians.

Although the retina has re-detached in two cases, the relevant observation in this preliminary short paper is that all eight aphakic eyes tolerated the presence of intravitreal air without complication.

\section{Summary}

The use of intravitreal air in eight patients with aphakic retinal detachment is described briefly.

Acknowledgements are due to Dr. C. R. S. Jackson for permission to manage and describe Cases 3 and 4, and to Dr. G. T. Millar for permission to manage and describe Case 8.

\section{References}

ARruga, H. (1936) Bull. Soc. franç. Ophtal., 49, 288

CHAWLA, H. B., and Birchall, c. H. (1973) Brit. 7. Ophthal. 57, 60

ROSENGREN, B. (1938) Acta ophthal. (Kbh.), 16, I 77

$\mathbf{F}$ 